\title{
Percutaneous bicaval dual lumen cannula for extracorporeal life support
}

\author{
Woojung Kim¹, Hye Won Kwon², Jooncheol Min', Sungkyu Cho', Jae Gun Kwak', June Dong Park², \\ Woong-Han Kim ${ }^{1}$
}

Departments of ${ }^{1}$ Thoracic and Cardiovascular Surgery and ${ }^{2}$ Pediatrics, Seoul National University Children's Hospital, Seoul National University College of Medicine, Seoul, Korea

Veno-venous extracorporeal membrane oxygenation (ECMO) is a useful mechanical device for pediatric patients with severe respiratory failure. Conventional veno-venous ECMO using double cannulation, however, is not feasible due to size limitations in pediatric patients who have small femoral vessels. Recently, percutaneous bicaval dual-lumen cannula can be inserted using single cannulation via the right internal jugular vein. Herein, we report the case of a pediatric patient with severe respiratory failure who was weaned off the ECMO successfully after treatment with bicaval dual-lumen cannulation for 5 days despite the small body size and immunocompromised condition due to chemotherapy for hemophagocytic lymphohistiocytosis.

Key Words: extracorporeal membrane oxygenation; pediatrics; respiratory insufficiency

Veno-venous extracorporeal membrane oxygenation (ECMO) is useful to patients with severe respiratory failure. Veno-venous ECMO is reported to provide better outcomes in neurological complication and survival than veno-arterial ECMO in respiratory failure [1]. However, conventional veno-venous ECMO cannulation is difficult in pediatric patients because they have smaller femoral veins than adults and ECMO flow rate is insufficient due to small femoral veins. Dual-lumen cannula (DLC; Avalon Elite, Maquet, Rastatt, Germany) could be a solution to this problem by using single cannulation in the right internal jugular vein (RIJV) in a pediatric patient. Herein, we report a pediatric case of acute respiratory failure successfully weaned from veno-venous ECMO using the DLC.

\section{CASE REPORT}

A 14-month-old boy (weight, $10.3 \mathrm{~kg}$; height, $75 \mathrm{~cm}$ ) with an underlying hematologic disease visited the emergency department due to 1-day fever associated with mild cough and sputum. He presented with fever $\left(39.2^{\circ} \mathrm{C}\right)$ and respiratory rate of 44 breaths per minute. He had been diagnosed with familial hemophagocytic lymphohistiocytosis (HLH) with c.754-1G >C homozygote at 73 days old, and he had received two cycles of induction chemotherapy including etoposide, cyclosporin-A, and dexamethasone. He was admitted to the pediatrics department and started with intravenous piperacillin-tazobactam, given his high risk for infection. After

\section{Case Report}

Received: May 30, 2019

Revised: August 25, 2019

Accepted: August 26, 2019

Corresponding author

Hye Won Kwon

Department of Pediatrics, Seoul

National University Children's

Hospital, Seoul National University

College of Medicine, 101 Daehak-ro,

Jongno-gu, Seoul 03080, Korea

Tel: +82-2-2072-4306

Fax: +82-2-747-2471

E-mail:drhwkwon@gmail.com

Copyright (@) 2020 The Korean Society of Critical Care Medicine

This is an Open Access article distributed under the terms of Creative Attributions Non-Commercial License (http:// creativecommons.org/li-censes/by-nc/4.0/ which permits unrestricted noncommercial use, distribution, and reproduction in any medium, provided the original work is properly cited. 
admission, he had high fever (up to $40.9^{\circ} \mathrm{C}$ ) and received teicoplanin, meropenem, and levofloxacin, but the fever $\left(38^{\circ} \mathrm{C}\right)$ persisted until hospital day (HD) 3. Neither bacteria nor virus was identified in his blood and sputum culture. On HD 15, he was diagnosed with a flare up of HLH, with the following signs: persistent fever, anemia (7.9 g/dl), thrombocytopenia (15,000/ml), elevated ferritin level $(10,195.79 \mathrm{ng} / \mathrm{ml})$, hypertriglyceridemia (226 mg/dl), and hypofibrinogenemia (143 mg/dl). Induction chemotherapy was restarted, and infliximab was administered for HLH reactivation. From HD 23, the fever subsided.

However, he had high fever on HD 80 and started to present tachypnea and desaturation on HD 83. At that time, influenza A was detected in the respiratory virus polymerase chain reaction (PCR) test; oseltamivir was administered immediately. Chest X-ray imaging showed rapid progression of bilateral lung haziness (Figure 1). Chest computed tomography showed increased bronchovascular bundle thickening in both lungs, suggestive of aggravation of bronchopneumonia (Figure 1). From HD 85, meropenem and trimethoprim-sulfamethoxazole were used empirically for bilateral lung haziness.

As his pulmonary condition deteriorated, the oxygen demand to maintain normal percutaneous oxygen saturation gradually
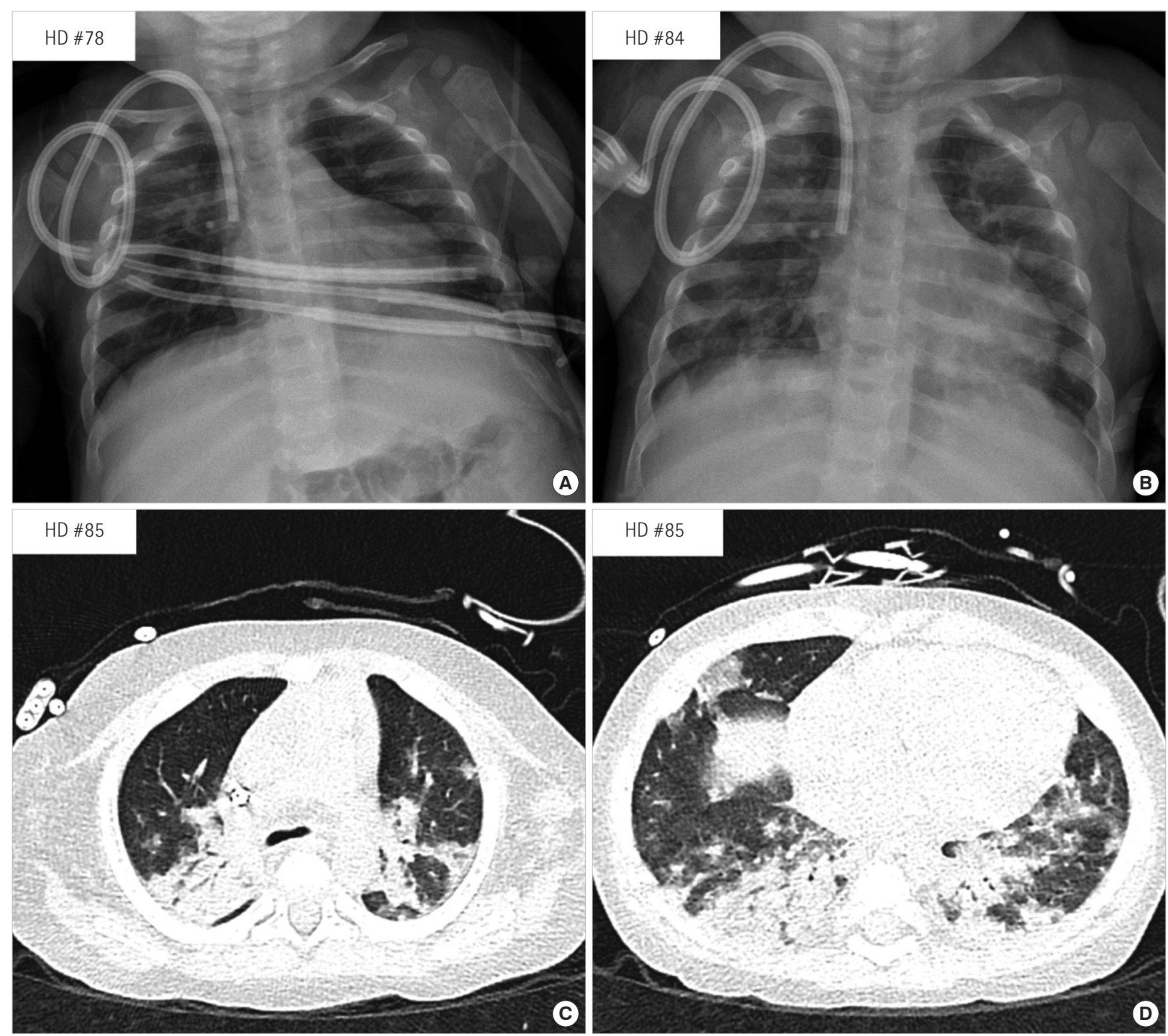

Figure 1. Chest X-ray images showing rapid progression of bilateral lung haziness (A: HD 78, B: HD 84), and (C, D) a chest computed tomography images showing increased bronchovascular bundle thickening in both lungs (HD 85 at 1 week before extracorporeal membrane oxygenation insertion). HD: hospital day. 
increased. A high-flow nasal cannula was applied on HD 87. On HD 91, percutaneous oxygen saturation decreased to $77 \%$ despite the high-flow nasal cannula which was set as a fraction of inspired oxygen $\left(\mathrm{FiO}_{2}\right)$ of 0.9 at $25 \mathrm{~L} / \mathrm{min}$. Emergent intubation was performed in the general ward, which took $38 \mathrm{~min}$ utes because of his difficult airway anatomy. During intubation, he experienced respiratory arrest and received cardiopulmonary resuscitation for 25 minutes. Spontaneous circulation returned thereafter, and he was transferred to the pediatric intensive care unit. Although the mechanical ventilator settings were in pressure-regulated volume control mode with $\mathrm{FiO}_{2}$, 1.0; positive end-expiratory pressure, $13 \mathrm{~cm} \mathrm{H}_{2} \mathrm{O}$; peak inspiratory pressure, $45 \mathrm{~cm} \mathrm{H}_{2} \mathrm{O}$; mean airway pressure, $25 \mathrm{~cm} \mathrm{H}_{2} \mathrm{O}$; respiratory rate, $60 / \mathrm{min}$; and tidal volume, $72 \mathrm{ml}$, arterial blood gas parameters were as follows: $\mathrm{pH}, 7.18 ; \mathrm{PaO}_{2}, 26 \mathrm{~mm} \mathrm{Hg}$; $\mathrm{PaCO}_{2}, 65 \mathrm{~mm} \mathrm{Hg}$; $\mathrm{O}_{2}$ saturation, 65\%. The oxygenation index was 70.7, and the $\mathrm{PaO}_{2} / \mathrm{FiO}_{2}$ ratio was 26.0. A hematologist evaluated that this patient could recover with hematopoietic stem cell transplantation after overcoming this crisis. Finally, veno-venous ECMO was decided 17 hours after cardiopulmonary resuscitation on HD 92.

Insertion of a 19-Fr DLC into the RIJV was decided. Since a Hickman catheter was placed in the RIJV, we inserted a new 5 -Fr central venous catheter in the right femoral vein. The Hickman catheter was removed just before DLC insertion, and we compressed the site where the Hickman catheter was removed for several minutes. After hemostasis, the RIJV was punctured using ultrasound-guided Seldinger technique, and a guide wire was inserted. However, we had difficulty inserting the dilator; thus, the DLC was inserted and fixed through a cut-down procedure. A tortuous guide wire was found at the previous Hickman catheter insertion site, which might be a cause of the difficult insertion of the dilator.

The initial ECMO pump flow was $1.2 \mathrm{~L} / \mathrm{min}$ with 2,500 revolutions per minute. The ECMO $\mathrm{FiO}_{2}$ and sweep gas flow rate were 1.0 and $650 \mathrm{ml} / \mathrm{min}$, respectively. The arterial blood gas improved with $\mathrm{pH} 7.37, \mathrm{PaO}_{2}$ of $72 \mathrm{~mm} \mathrm{Hg}$, and $\mathrm{PaCO}_{2}$ of 48 mm Hg 1 hour after ECMO insertion. We could reduce the $\mathrm{FiO}_{2}$ setting of the ventilator from 1.0 to 0.6 and lower the peak inspiratory pressure from 45 to $32 \mathrm{~cm} \mathrm{H}_{2} \mathrm{O}$. The oxygenation index improved to 16.7. Through echocardiography and chest Xray observation, the cannula was positioned in the right ventricle. Thus, the cannula was repositioned and placed in the inferior vena cava (IVC) (Figure 2). Sedation was done with remifentanil, midazolam, and vecuronium to prevent accidental decannulation.

On the day of ECMO cannula insertion (HD 92), intravenous peramivir was administered because of persistent positive PCR results for the influenza A virus. Intravenous gamma-globulin was administered because we could not exclude other bacterial sepsis. Both pupils were round and $3 \mathrm{~mm}$ in diameter; pupil light reflex was prompted before and after ECMO insertion. As
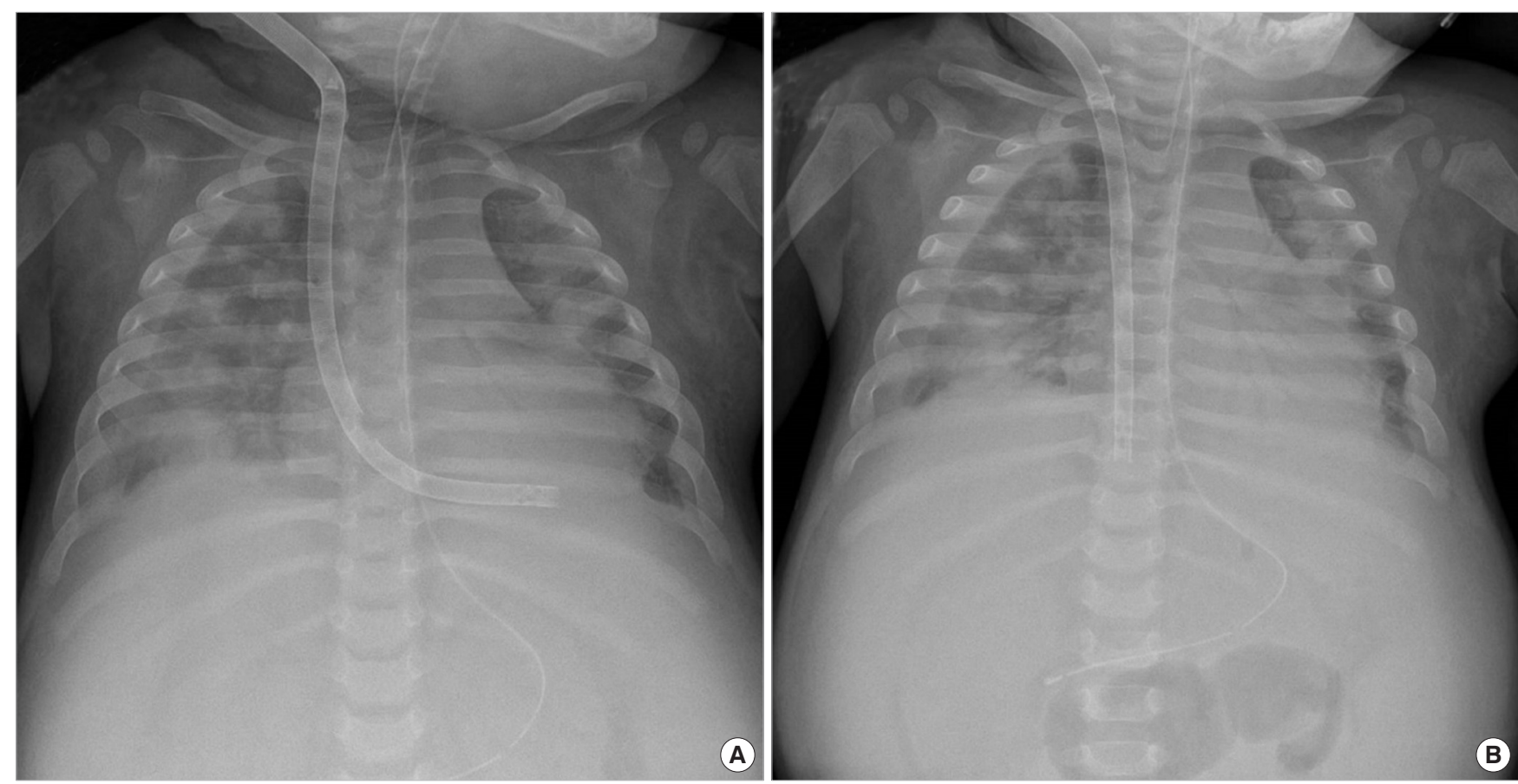

Figure 2. After checking the cannula in the right ventricle on chest X-ray (A), the cannula was repositioned to the inferior vena cava (B). 
his body weight increased to $12.1 \mathrm{~kg}$ after resuscitation, we started continuous infusion of furosemide at a rate of $0.1 \mathrm{mg} / \mathrm{kg} / \mathrm{hr}$ the day before the ECMO insertion. Although his urine output was maintained at $2-5 \mathrm{ml} / \mathrm{kg} / \mathrm{hr}$, serum creatinine level was elevated from 0.58 to $0.83 \mathrm{mg} / \mathrm{dl}$, serum calcium decreased from 7.6 to $6.8 \mathrm{mg} / \mathrm{dl}$, phosphorus increased from 7.3 to 10.0 $\mathrm{mg} / \mathrm{dl}$, and potassium increased from 4.4 to $6.4 \mathrm{mmol} / \mathrm{L}$ after ECMO insertion. Therefore, continuous renal replacement therapy was added to the extracorporeal circuit to maintain fluid and electrolyte balance. On ECMO day 2, we could decrease ECMO $\mathrm{FiO}_{2}$ and sweep gas flow rate to 0.21 and $300 \mathrm{ml} / \mathrm{min}$, respectively. The ECMO pump flow was properly maintained, during ECMO support (Figure 3). On ECMO day 5 (HD 97), the arterial blood gas parameters were as follows: $\mathrm{pH}, 7.37 ; \mathrm{PaO}_{2}$,

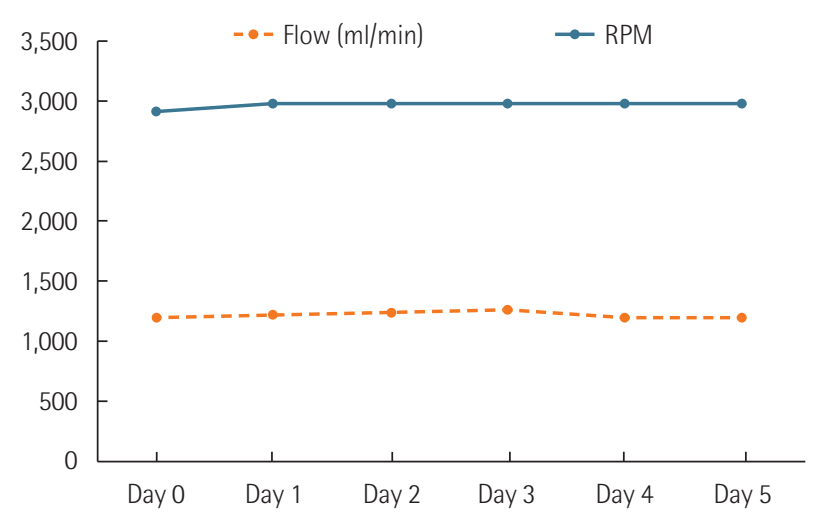

Figure 3. Graph showing the flow of extracorporeal membrane oxygenation and revolution per minute for 5 days.

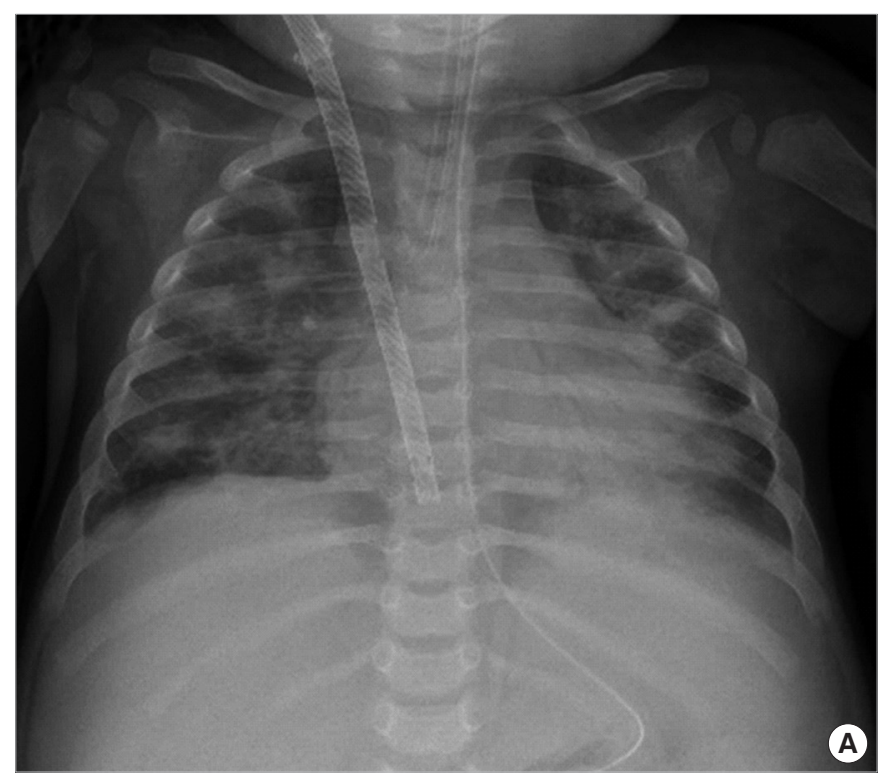

75.1 mm Hg; $\mathrm{PaCO}_{2}$, 45.9 mm Hg; oxygen saturation, 95.7\%, and the ventilator settings were set in pressure-regulated volume control mode as follows: $\mathrm{FiO}_{2}, 0.4$; peak end expiratory pressure, $11 \mathrm{~cm} \mathrm{H}_{2} \mathrm{O}$; peak inspiration pressure, $25 \mathrm{~cm} \mathrm{H}_{2} \mathrm{O}$; mean airway pressure, $17 \mathrm{~cm} \mathrm{H}_{2} \mathrm{O}$; respiratory rate, 40 breaths/ min; and tidal volume, $56 \mathrm{ml}$. The oxygenation index was 6.7, and $\mathrm{PaO}_{2} / \mathrm{FiO}_{2}$ ratio was 187.8. Chest X-ray imaging showed improved bilateral lung haziness (Figure 4). Because the arterial blood gas parameters were remained stable at minimal setting of $\mathrm{ECMO}\left(\mathrm{FiO}_{2}\right.$ as 0.21 and sweep gas flow rate as $\left.0 \mathrm{ml} / \mathrm{min}\right)$ for 24 hours, ECMO weaning was decided on ECMO day 6 (HD 98). After decannulation of the DLC, the cannulation site was repaired with Heineke-Mikulicz technique, and a new 8-Fr catheter for continuous renal replacement therapy was inserted into the RIJV above the previous cannulation site (Figure 4). Surgical complications such as vascular injury and bleeding did not occur. After ECMO weaning, his vital signs were stable as follows: blood pressure, 100/54 mm Hg; heart rate, 128 beats/min; and $\mathrm{SpO}_{2}, 96 \%$ in the same ventilator settings as before ECMO weaning. Spontaneous eye opening was confirmed after discontinuation of vecuronium although we did not perform brain imaging study.

During ECMO, intravenous heparin was maintained with a target activated partial thromboplastin time of 55-70 seconds for anticoagulation. He required daily platelet transfusion to keep the platelet count $>80,000 / \mathrm{ml}$ during ECMO. There was small amount of melena during ECMO on HD 96, which improved after ECMO weaning. Culture studies before and during ECMO were negative for bacteria, and there was no infec-

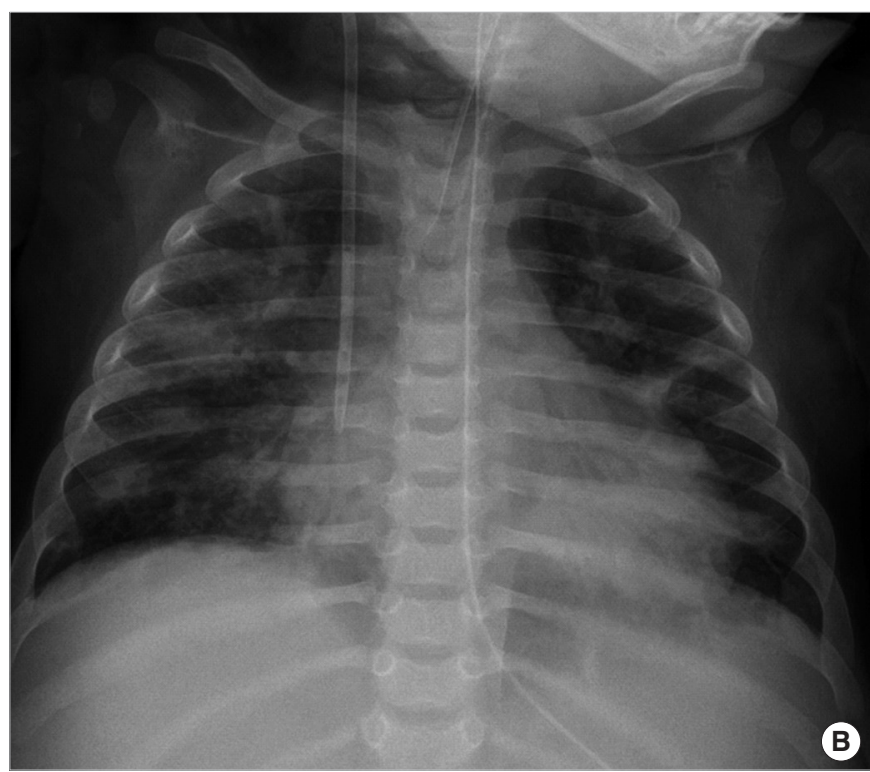

Figure 4. Chest X-ray image showing improved bilateral lung haziness. Chest X-ray just before (A) and after (B) decannulation. 
tion sign such as fever and elevated C-reactive protein during ECMO.

On HD 99, because the blood test showed elevated C-reactive protein $(27.9 \mathrm{mg} / \mathrm{dl}$ from $1.0 \mathrm{mg} / \mathrm{dl}$ on HD 97) without fever, we performed blood culture and added voriconazole to treat possible fungal infection. Unfortunately, Gram-negative rods were detected in the blood culture, and colistin was added on HD 100. The pathogen was identified as carbapenemresistant Acinetobacter baumannii on HD 102. Despite $>48$ hours of colistin administration, the bacteria was continuously detected in blood culture. His blood pressure dropped to 65/32 $\mathrm{mm} \mathrm{Hg}$ despite the high-dose inotropic support (epinephrine $0.6 \mu \mathrm{g} / \mathrm{kg} / \mathrm{min}$, norepinephrine $0.6 \mu \mathrm{g} / \mathrm{kg} / \mathrm{min}$, dobutamine 20 $\mu \mathrm{g} / \mathrm{kg} / \mathrm{min}$ ) and did not recover even with bolus injection of $100 \mu \mathrm{g}$ of epinephrine. The parents of the patient signed to "Do not resuscitate": and the patient eventually expired on HD 103.

\section{DISCUSSION}

Veno-venous ECMO is an option for patients with severe respiratory failure. The most common cause of respiratory failure is viral pneumonia, similar to the present case [2]. In small children, insertion of the veno-venous ECMO cannula is not easy because their femoral vessels have small diameters. Therefore, surgeons often performed veno-arterial ECMO cannulation via the internal jugular vein and carotid artery or central ECMO cannulation after sternotomy. However, neurologic complications were higher in veno-arterial cannulation than in veno-venous cannulation [1]. Recently, veno-venous ECMO using the DLC has been reported as an efficient tool in aiding pediatric patients with respiratory failure, as in the present case $[3,4]$.

The DLC has a bicaval design for lower recirculation and a wire-covered double lumen to prevent kinking (Figure 5). Since the DLC was inserted into the RIJV, we could avoid cannularelated complications that result from femoral cannulation such as infection and vascular injury $[5,6]$. Furthermore, a single cannula insertion requires less time compared to two cannula insertions in an emergent situation. As positioning in a prone or seated position is less limited, we can provide better lung care. Because an effective ECMO flow can be persistently maintained, this may not be inferior to veno-venous ECMO using two cannulas.

Some important factors must be taken into consideration with DLC insertion. DLC is placed through the superior vena cava (SVC) into the right atrium and the IVC. Most importantly, the return hole must be placed toward the tricuspid valve,

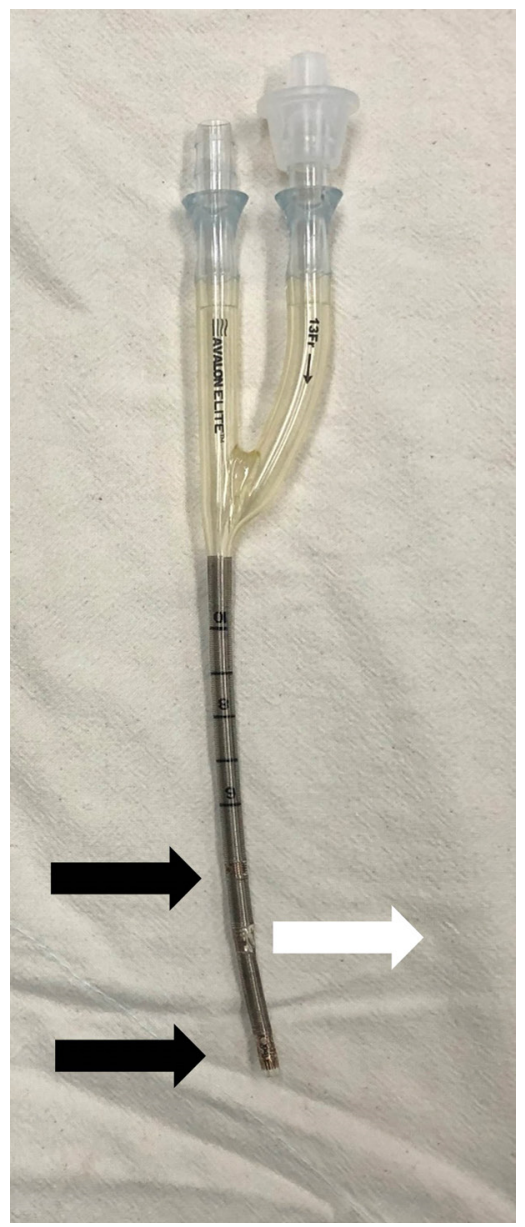

Figure 5. The bicaval dual lumen cannula is designed for low recirculation and has a wire-covered double lumen to prevent kinking. The return hole should be placed toward the tricuspid valve (white arrow), and the drain hole in the superior vena cava and inferior vena cava (black arrows).

in between the SVC and IVC (Figure 5). Echocardiography or fluoroscopy guidance may help with appropriate cannula insertion $[7,8]$. In this case, chest X-ray and echocardiography showed that the DLC had been placed in the right ventricle through the tricuspid valve, not in the IVC, requiring repositioning.

In this case, severe respiratory failure related to viral pneumonia served as an indication for ECMO insertion. ECMO was started to help overcome this temporary respiratory failure. Finally, with improvement of respiratory failure, the patient was successfully weaned from the veno-venous ECMO, even though he expired due to refractory septic shock because of his immunocompromised state after ECMO weaning.

The present case shows that veno-venous ECMO using DLC could be a good option for respiratory failure in pediatric patients. Currently, DLCs cannot be imported easily; they can be 
imported from the United States and used individually after obtaining permission from the Ministry of Food and Drug Safety. The approval process usually takes 2 months. In this case, we could use the DLC prepared previously for a patient who expired due to respiratory failure before the present patient's DLC arrived. We hope that DLC will be officially imported and registered in the National Health Insurance Service so that it can be used by more children with respiratory failure.

\section{CONFLICT OF INTEREST}

No potential conflict of interest relevant to this article was reported.

\section{ORCID}

Woojung Kim

Hye Won Kwon

Jooncheol Min

Sungkyu Cho

Jae Gun Kwak

June Dong Park

Woong-Han Kim https://orcid.org/0000-0001-9530-8638

https://orcid.org/0000-0002-4949-9688

https://orcid.org/0000-0001-9446-4903

https://orcid.org/0000-0003-0492-2814

https://orcid.org/0000-0002-6375-1210

https://orcid.org/0000-0001-8113-1384

https://orcid.org/0000-0003-2837-7929

\section{AUTHOR CONTRIBUTIONS}

Conceptualization: HWK, WHK. Data curation: WK, HWK. Formal analysis: HWK. Methodology: JM, SC, JGK. Project administration: JDP, WHK. Visualization: WK, HWK. Writing original draft: WK. Writing - review \& editing: HWK.

\section{REFERENCES}

1. Carpenter JL, Yu YR, Cass DL, Olutoye OO, Thomas JA, Burgman $\mathrm{C}$, et al. Use of venovenous ECMO for neonatal and pediatric ECMO: a decade of experience at a tertiary children's hospital. Pediatr Surg Int 2018;34:263-8.

2. Brogan TV, Lequier L, Lorusso R, MacLaren G, Peek G. Extracorporeal life support: the ELSO red book. 5th ed. Ann Arbor: Extracorporeal Life Support Organization; 2017.

3. Speggiorin S, Robinson SG, Harvey C, Westrope C, Faulkner GM, Kirkland P, et al. Experience with the Avalon ${ }^{\circledR}$ bicaval double-lumen veno-venous cannula for neonatal respiratory ECMO. Perfusion 2015;30:250-4.

4. Fallon SC, Shekerdemian LS, Olutoye OO, Cass DL, Zamora IJ, Nguyen T, et al. Initial experience with single-vessel cannulation for venovenous extracorporeal membrane oxygenation in pediatric respiratory failure. Pediatr Crit Care Med 2013;14: 366-73.

5. Bermudez CA, Rocha RV, Sappington PL, Toyoda Y, Murray $\mathrm{HN}$, Boujoukos AJ. Initial experience with single cannulation for venovenous extracorporeal oxygenation in adults. Ann Thorac Surg 2010;90:991-5.

6. Javidfar J, Brodie D, Wang D, Ibrahimiye AN, Yang J, Zwischenberger JB, et al. Use of bicaval dual-lumen catheter for adult venovenous extracorporeal membrane oxygenation. Ann Thorac Surg 2011;91:1763-8.

7. Salazar PA, Blitzer D, Dolejs SC, Parent JJ, Gray BW. Echocardiographic guidance during neonatal and pediatric jugular cannulation for ECMO. J Surg Res 2018;232:517-23.

8. Jarboe MD, Gadepalli SK, Church JT, Arnold MA, Hirschl RB, Mychaliska GB. Avalon catheters in pediatric patients requiring ECMO: placement and migration problems. J Pediatr Surg 2018;53:159-62. 